Part of Journal of Research of the National Bureau of Standards, Volume 15, September 1935

\title{
INFRARED ABSORPTION SPECTRA OF PLANT AND ANI- MAL TISSUE AND OF VARIOUS OTHER SUBSTANCES
}

\author{
By R. Stair and W. W. Coblentz
}

\section{ABSTRACT}

Supplementing a previous report on plant pigments (BS Research Paper 617) the present paper describes new data on the infrared absorption spectra of plant and animal substances (cellulose and proteins) as found in nature and, in some cases, in the form of pure material prepared in the laboratory.

The data were obtained by means of a mirror spectrometer, portable vacuum thermopile, and ironclad Thomson galvanometer, described in previous publications. The region of the infrared spectrum extending to $15 \mu$ was examined.

Outstanding among the plant substances examined are samples of pure rubber, and associated materials - styrene, indene, polystyrene, and polyindene.

The cellulose materials examined included Cellophane (commercial preparation), onion skin, translucent membrane of pith of pokeweed, the seed septum of moonwort, and the seed wing of the cotton tree.

The protein materials examined included dried specimens of chitin (the outer integument of insects), pith of feathers, air bladder of fish, bat's wings, film of dried egg albumin, commercial gelatin, lining of egg shell, and wing of a dragon fly.

The miscellaneous substances reported upon are polyvinyl acetate and polyvinyl chloracetate resins, glyptal resin, shellac, and a group of substances of interest in connection with the Raman effect.

I. Introduction

II. Instruments and methods

III. Spectral-transmission data on plant and animal substances_._.

1. Rubber and associated substances......... 298

2. Cellulose materials

3. Proteins

IV. Spectral-transmission data on miscellaneous substances

V. References_._. 316

\section{INTRODUCTION}

An important contribution to science is the determination of the effect of chemical constitution upon the spectral absorption of a substance.

Every substance, whether element or chemical compound, has a characteristic absorption spectrum. That is to say, the absorption spectrum of a compound is not the composite of the bands of selective absorption of the constituent elements. While this proposition is now accepted as axiomatic, it was an outstanding question among the early investigators in this field.

In recent years data on infrared absorption spectra have found important commercial and theoretical application, for example, the 
Raman effect. Hence as time permits, and as characteristic material becomes available, data are being obtained on the infrared absorption speetra of various substances.

The present paper contributes new data to the gradually increasing store of information regarding characteristic absorption spectra of substances found in nature and, in some cases, prepared in a pure state in the laboratory. Among these substances are various forms of rubber, cellulose, and protein.

This paper gives data also on substances which were examined some years ago in connection with Raman's [1] ${ }^{1}$ discovery that, in scattered radiation, the frequency difference between the companion line and the exciting line is constant and is equal to the frequency of an infrared absorption band.

The part of this investigation relating to plant pigments was reported in a preceding paper [2], to which reference is made for a condensed summary of the present-day theoretical aspects of infrared absorption.

It will therefore suffice to recall that the present-day conception of the mechanism of absorption assumes each absorption band to be a fundamental, a harmonic, or a combination effect, involving vibrational and rotational states of the molecule.

The earlier observations [11] of approximately harmonic absorption bands (for example the absorption bands of hydrocarbons, at 0.86, $1.71,3.43,6.86$, and 13.8 to $14 \mu$ ) have thus found a place in presentday speculations; but not, however, without some distortion of numerical values.

For example, some writers have used the value $6.90 \mu$, (the maximum of an absorption band of hydrocarbons) because, as a fundamental, it fits the formula better than the observed value $6.86 \mu$ in spite of the fact that the best calibration data available indicate that the observed value is the more probable.

With the limited data at hand at that time, the most definite inference that could be emphasized by the earlier investigators was that certain absorption bands are caused by particular groups of atoms (for example $\mathrm{CH}_{2}, \mathrm{CH}_{3}, \mathrm{OH}$, and $\mathrm{COOH}$ groups) although the bonding of the atoms (for example $\mathrm{C}=\mathrm{O}$ ) was also mentioned [3]. Recent writers, supplied with more varied data, are inclined to assign the cause of absorption principally to the bonding or linkage of the atoms, e. g., the "C-H linkage" or the "N-H linkage." This, of course, as already mentioned, was evident, but not stressed, in the earlier conclusions [4] on the effect of the arrangement of the atoms in the molecule (e. g., compounds having NCS or SCN radicles) and in the chain compounds where the position of the maxima of absorption remained unchanged whether the compound contained 6 C-atoms and $14 \mathrm{H}$-atoms or $24 \mathrm{C}$-atoms and $50 \mathrm{H}$-atoms [11]. In some cases the terms "groups" and "bonds" were used synonymously, showing looseness in terminology instead of actual differences in ideas.

The foregoing conclusions are based upon studies of substances having a fairly simple atomic structure. As was to be expected, subsequent studies of the absorption system of highly complex molecular structures, such as obtain in the aniline dyes [5], indicated so great a complexity that no definite conclusions could be drawn regarding the identification of certain absorption bands with certain

${ }_{1}$ Numbers in brackets refer to the list of references at the end of this paper. 
groups of atoms. A similar condition was found in the absorption spectra of plant pigments previously reported [2] and in some of the herein-described substances.

\section{INSTRUMENTS AND METHODS}

Reference is made to previous publications [2, 6, 7, 8, 9] for a more detailed description of the experimental procedure.

The spectroradiometer consisted of a spectrometer with mirrors $50 \mathrm{~cm}$ in focal length. In some of the work a fluorite prism was used for exploring the spectrum from 1 to $7 \mu$, and a rock-salt prism for the region of 7 to $15 \mu$.

A portable vacuum thermopile of bismuth-silver, connected with an ironclad Thomson galvanometer, was used for measuring the spectral radiation. The source of radiation was a Nernst glower, focused upon the entrance slit of the spectrometer by means of a large concave mirror of $1 \mathrm{~m}$ focal length. The ratio of the galvanometer deflection observed when the specimen was placed in front of the spectrometer slit to the deflection observed when the material was out of the optical path gives the percentage transmission depicted in the illustrations. No correction was made for scattering, which accounts for the low values of the transmissions of the inhomogeneous materials in the short wave lengths.

The containers for the liquids or vapors were made of cleavage plates of rock salt or polished plates of fluorite, placed at the entrance slit. Variations from the standard procedure are noted in the text.

A very thin (capillary) film of a liquid was obtained by splitting a crystal of rock salt (size 5 by 3 by $1 \mathrm{~cm}$ ) into two parts, each $5 \mathrm{~mm}$ in thickness, reassembling it accurately, and placing a drop of the liquid in a conical or $V$-shaped depression, cut into one side, along the line of cleavage of the crystal. By capillary action the film of liquid spreads uniformly, without interruptions by air bubbles, between the two plates.

The samples of animal and vegetable tissue were mounted over openings ( 5 to $8 \mathrm{~mm}$ wide by 15 to $20 \mathrm{~mm}$ long) cut into pieces of cardboard (index card), which were supported on a movable mounting in front of the entrance slit of the spectrometer.

The thicknesses of the samples were varied in order to produce greater contrasts between the absorption bands and the intervening more transparent parts of the spectrum. In certain cases where the material was deposited on a plate of rock salt, the thickness of the layer examined could not be accurately determined.

The data of interest in connection with the question of the Raman scattering of radiation were obtained on very pure materials (figs. 19 to 27, inclusive), some of which were prepared by Prof. J. Timmermans of the University of Brussels, Belgium, and deposited at this Bureau.

\section{SPECTRAL-TRANSMISSION DATA ON PLANT AND ANIMAL SUBSTANCES}

Under this caption are given the infrared spectral transmission curves of animal and vegetable (protein and cellulose) tissue, and, in some cases, of similar material after having undergone purification 
(modification) in the laboratory. In view of the difficulty in procuring homogeneous material, the scope of the inquiry is necessarily restricted. Fortunately, a few natural plant and animal substances are available which, in the dry state, are relatively homogeneous.

\section{RUBBER AND ASSOCIATED SUBSTANCES}

Rubber is a hydrocarbon complex of $\mathrm{CH}, \mathrm{CH}_{2}$, and $\mathrm{CH}_{3}$ groups. Hence, the freshly prepared material should and does show the bands of selective absorption characteristic of these groups of atoms.

The material examined was very generously supplied by $W$. Harold Smith [12], of the Chemistry Division of this Bureau, who purified the rubber by crystallization. The samples of ether-soluble (alpha) rubber and of the ether-insoluble (beta) rubber were prepared by a method of purifying and fractionating of rubber from Hevea

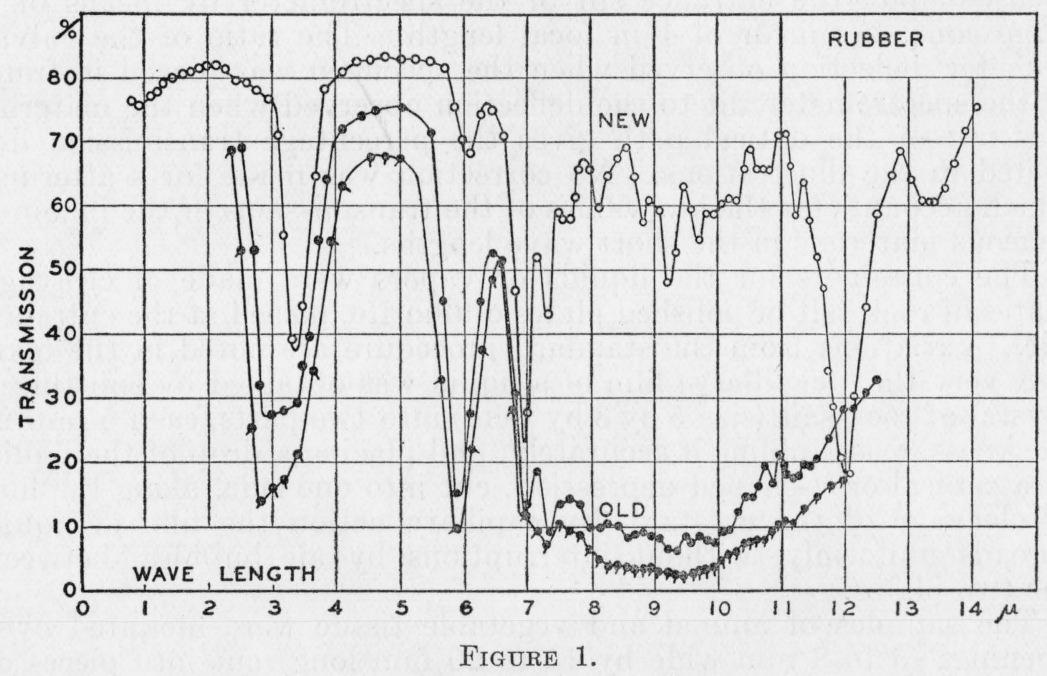

latex, described in National Bureau of Standards Research Paper RP544 [12].

Suitable films were deposited from solutions of each fraction. Unfortunately, data on the undissolved, ether-insoluble fraction could not be included because films of this material, of the proper thickness, must be made by a special process, with apparatus that was not available.

The infrared transmission spectrum is of interest in connection with the study of the preparation of synthetic rubber or other material of similar physical nature.

\section{(a) PURE RUBBER}

In figure 1 are depicted the spectral-transmission curves of a film of rubber (containing the unseparated alpha- and beta-components, which were present in the ratio of $3: 1$, respectively) when freshly prepared and after aging for 7 and 16 months, respectively, in a glass container and at laboratory temperature. 
The sample consisted of a solution of the rubber dissolved in a mixture of xylol and ether, a small amount of which was placed upon a plate of rock salt. The solvents were removed by keeping the rocksalt plate in an evacuated chamber for several days prior to the spectral examination.

In addition to the usual hydrocarbon bands at $3.43,6.95$ (usually 6.86 ), and at $7.3 \mu$, respectively, the small absorption band at $6 \mu$ and the large band at $12.0 \mu$ are to be noted.

As the sample changes by aging (oxidation) the infrared absorption is greatly changed. The strong absorption band at $12 \mu$ is submerged by the heavy absorption throughout this spectral region.

On the other hand, the small absorption bands, in the region of $2.8 \mu$ and at $6 \mu$ (observable in the fresh material), which are indicative of hydrocarbons modified by $\mathrm{OH}$-groups and oxygen, became the most

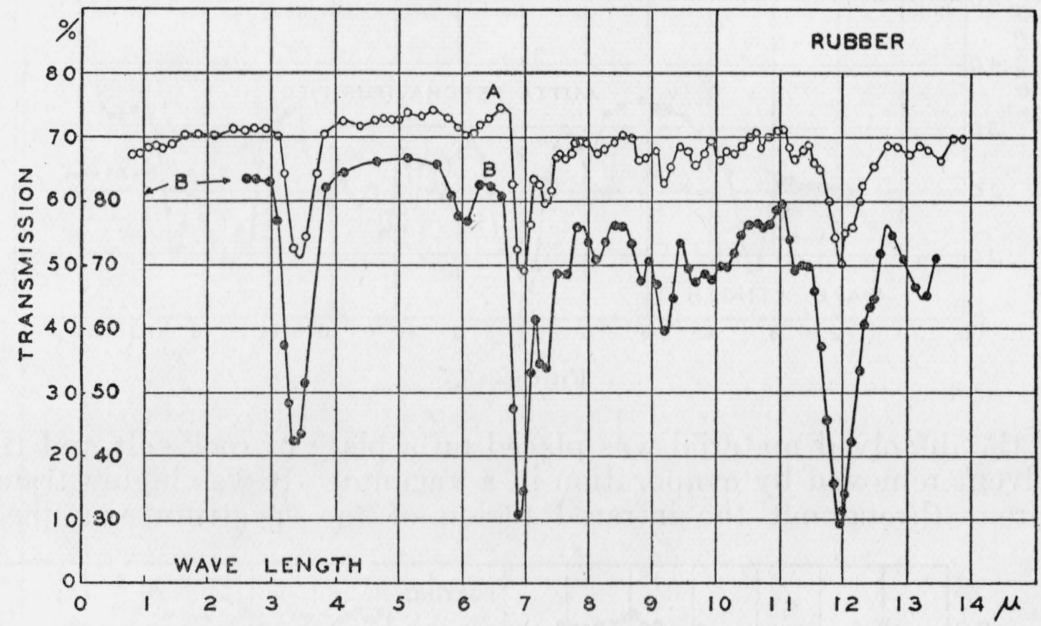

Figure 2.

conspicuous absorption maxima (at 2.9 and $5.9 \mu$, respectively) in the infrared spectrum of the aged material.

The spectral absorption of separated samples of alpha (A) and beta (B) rubber are illustrated in figure 2 . The close agreement between these 2 curves and that of figure 1 is significant. Evidently, on the basis of this analysis, the two forms of rubber have a very similar molecular structure.

The large absorption band at $12 \mu$ found in ethane, $\mathrm{C}_{2} \mathrm{H}_{6}$ [11] and the ever-recurring maxima at $3.45,6.9$, and $7.3 \mu$ are to be noted.

An examination of a sample of the beta material, in the ultraviolet spectrum, indicated a high transmission extending from the visible region to $365 \mathrm{~m} \mu$. For wave lengths shorter than $365 \mathrm{~m} \mu$ the sample showed a decrease in transmission to about $250 \mathrm{~m} \mu$, where it was completely opaque.

(b) PURE GUTTA-PERCHA HYDROCARBON

The sample examined was a translucent film about $0.07 \mathrm{~mm}$ in thickness. It was prepared by successive crystallizations from a solution in petroleum ether. 
The spectral transmission curve is shown in figure 3. There is a close resemblance to rubber only for wave lengths shorter than $10 \mu$.

\section{(c) PURE BALATA HYDROCARBON}

This sample was purified by the same process employed with guttapercha. A thin film (probably 0.01 to $0.02 \mathrm{~mm}$ thickness when dried)

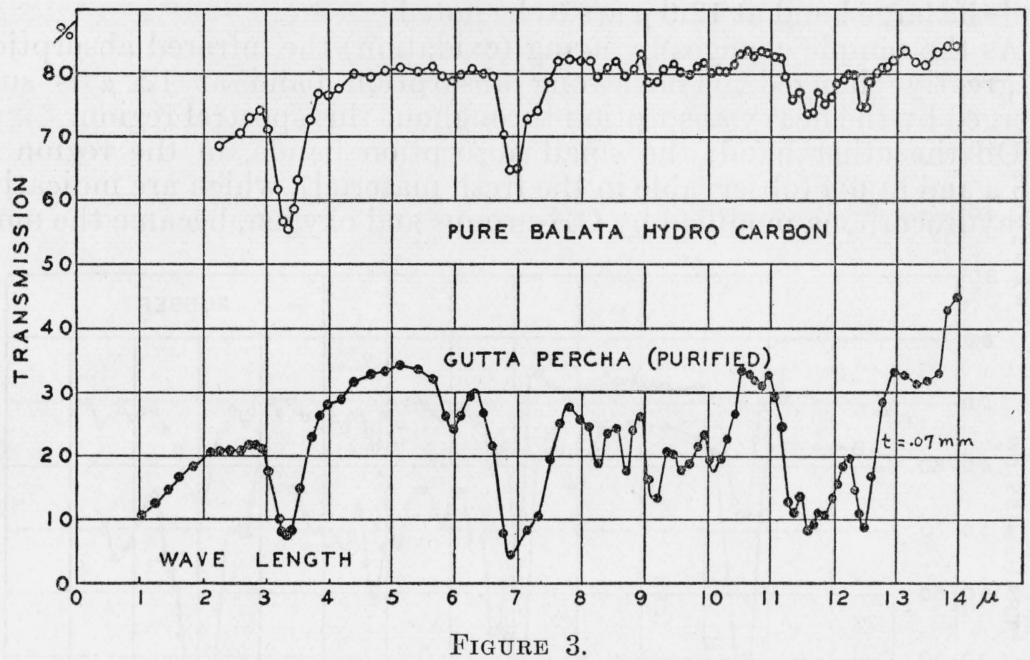

of the dissolved material was placed on a plate of rock salt and the solvent removed by evaporation in a vacuum. It was highly transparent throughout the infrared region of the spectrum examined.

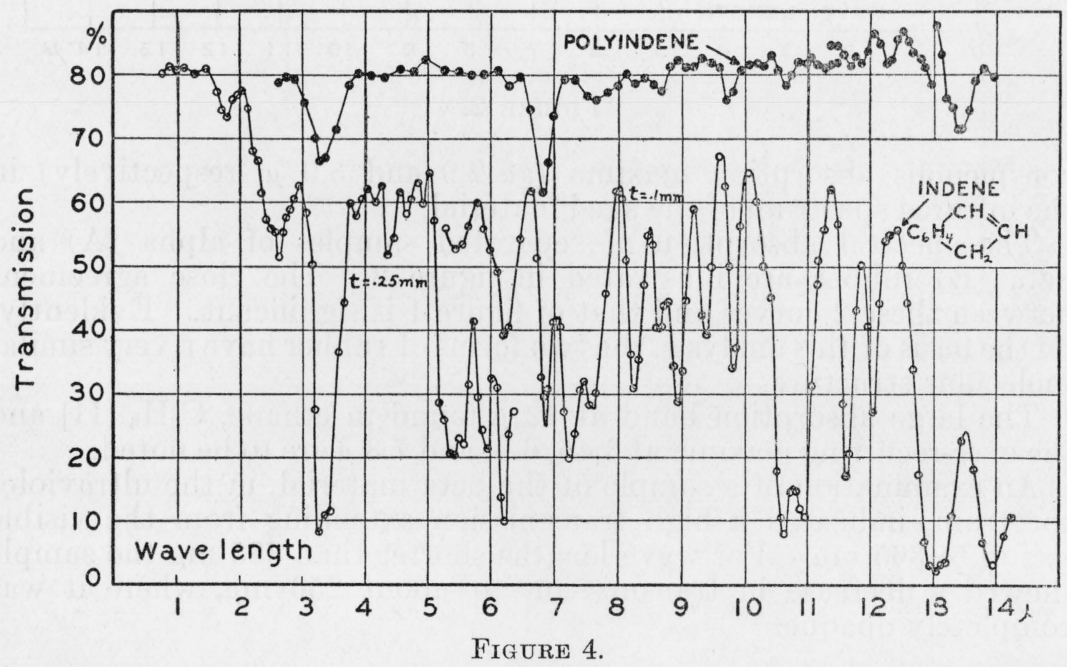

The absorption bands (fig. 3) resemble very closely those of guttapercha, which indicates a similarity in chemical constitution as found by chemical tests. 
(d) POLYINDENE AND POLYSTYRENE

The polyindene (fig. 4) and polystyrene (fig. 6) were prepared by the action of 85 percent sulphuric acid at $0^{\circ} \mathrm{C}$, using the method of Brooks and Humphrey [13]. The preparation of these polymers was

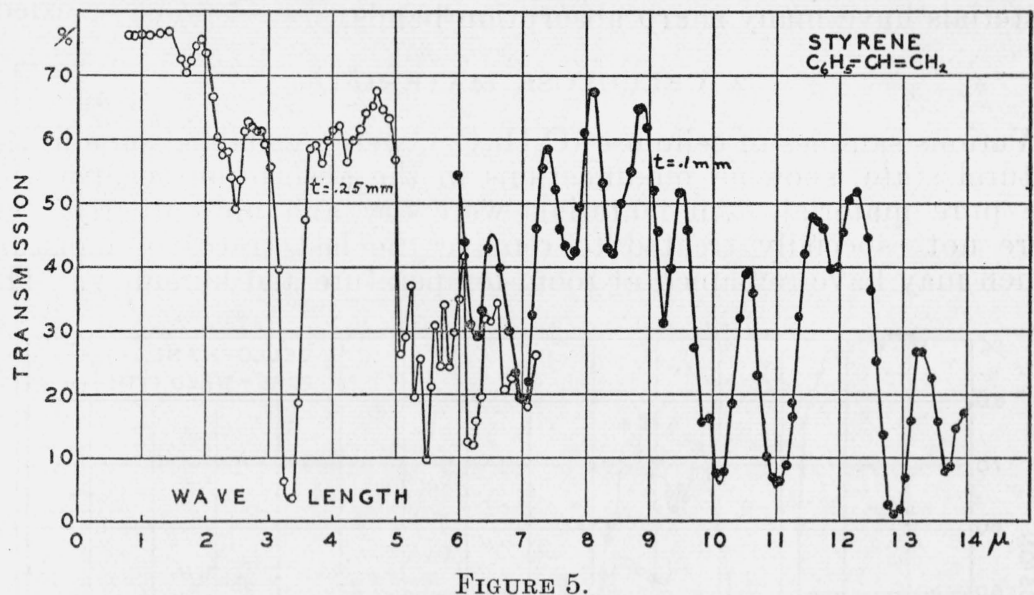

not rigidly controlled with the object of obtaining reproducible material. The data on transmission are intended merely to show the direction of the change brought about by polymerization.

The sample of polyindene examined consisted of a film of the material (thickness about $0.01 \mathrm{~mm}$ ) on a plate of rock salt. It was depos-

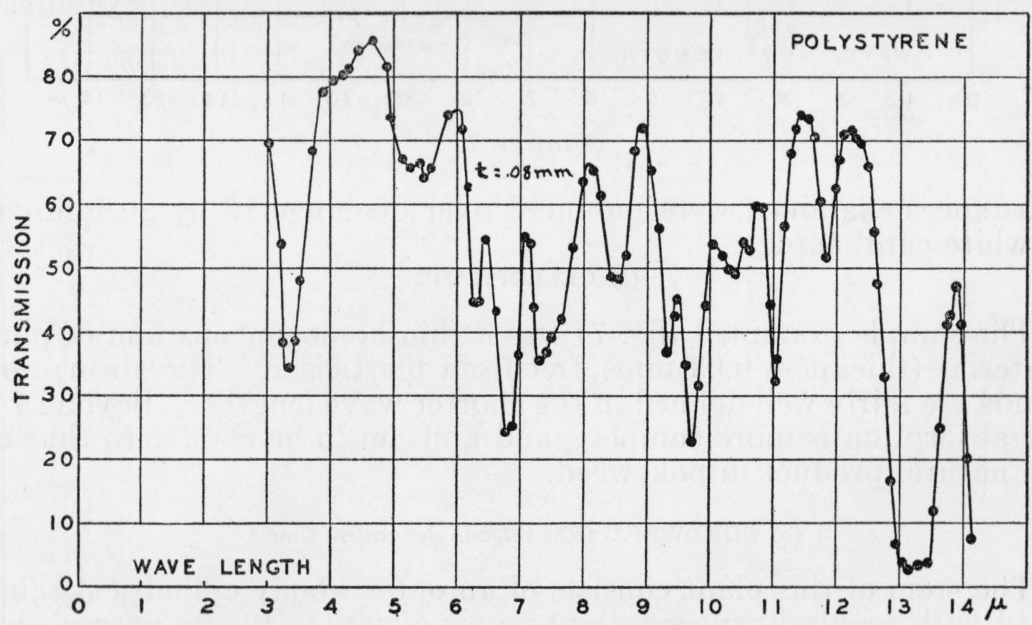

FIGURE 6.

ited with a volatile solvent which was removed by keeping the sample in a vacuum for several days.

A transparent film of polystyrene was prepared in a similar manner but removed from the plate. The sample (thickness $0.08 \mathrm{~mm}$ ) was mounted over an opening in a cardboard for examination. 
(e) STYRENE AND INDENE

The styrene (fig. 5) and indene (fig. 4) examined were pure materials having boiling points and densities in conformity with the values given by Beilstein [14]. Acknowledgment is due to the Ciba Co., Inc., New York, N. Y., for a sample of indene of high purity. Both materials have many sharp absorption bands.

\section{CELLULOSE MATERIALS}

Various samples of cellulose $\left(\mathrm{C}_{6} \mathrm{H}_{10} \mathrm{O}_{5}\right)_{x}$ were available, some in the natural state, showing modifications in the absorption spectrum of the pure material. All materials were dry and unweathered, but were not especially treated to remove the last traces of moisture which may have remained at room temperature and humidity. The

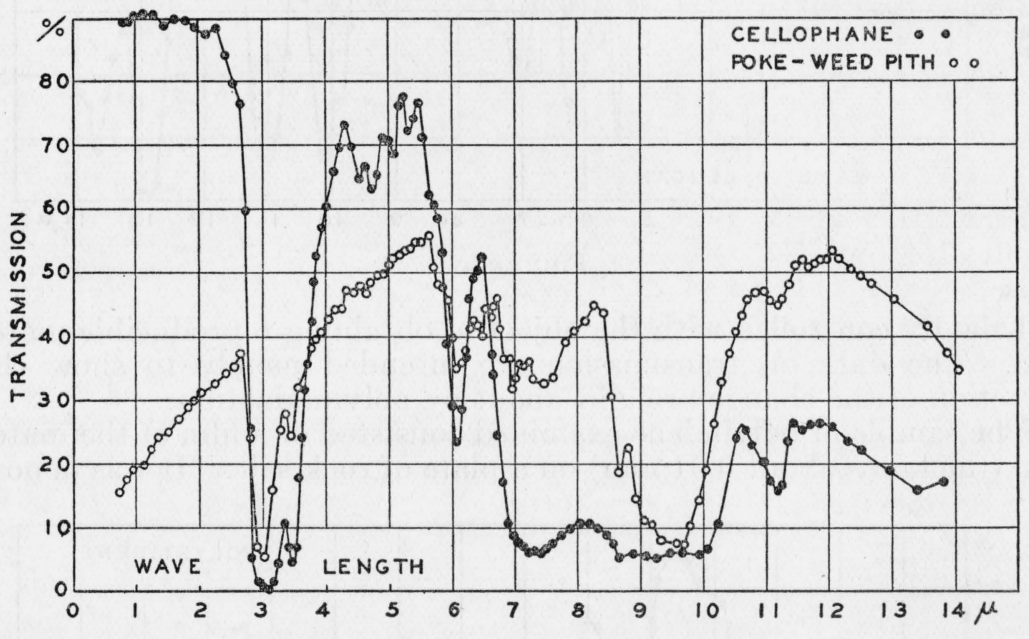

FIgURe 7.

substances examined were mounted over openings 10 by $20 \mathrm{~mm}$ cut in white cardboard.

(a) CELlophane

The sample examined (fig. 7) was a thin homogeneous film of pure material (thickness $0.03 \mathrm{~mm}$ ), free from plasticizer. The absorption bands are fairly well defined in the shorter wave lengths. Beyond $7 \mu$ the absorption is more complex, and appears to be similar to that of the natural product in pokeweed.

(b) POKEWEED (Phytolacca decandra, Linn.)

The stem of this plant consists of an outer woody cylindrical tube, filled with regularly spaced diaphragms of pith. In the natural dry state the central portion of each diaphragm (1 to $2 \mathrm{~cm}$ in diameter) consists of a thin translucent membrane.

The absorption spectrum (fig. 7) closely resembles that of cellophane. The reduced height of the ordinates in the shorter wave lengths is the result of scattering of radiation by the pith, for which no correction has been made. 
(c) ONION SKIN

Several specimens of onion skin were examined. Samples A and B (fig. 8) were pieces of dry integument from the outside of the bulb. Curve $\mathrm{C}$ depicts the spectral transmission of the thin membrane that grows between the fleshy scale-leaves of a young onion bulb. This

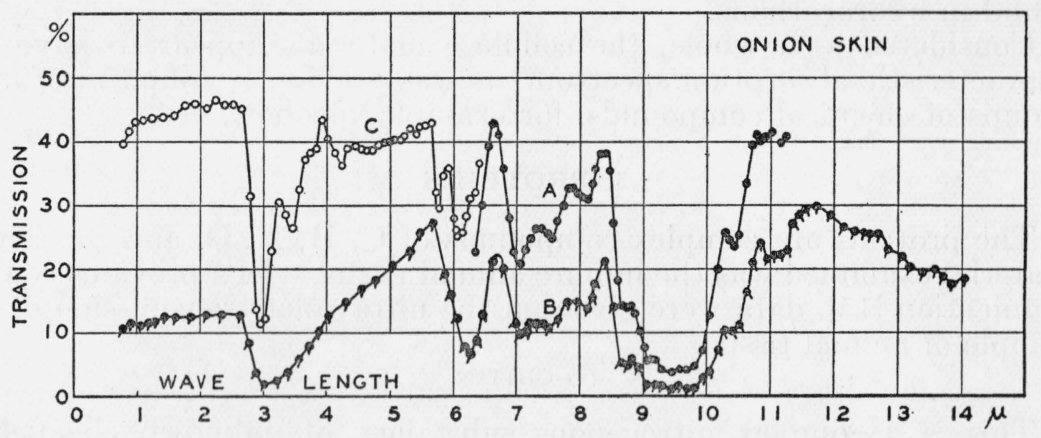

Figure 8.

membrane was mounted over an opening cut in a cardboard support and allowed to dry for 3 days before it was examined. The close resemblance between these transmission curves and those of Cellophane and of pokeweed pith is to be noted.

\section{(d) SEED SEPTUM}

The specimen examined was obtained from the seed pod of moonwort (Lunaria biennis), the longest dimension being about $25 \mathrm{~mm}$.

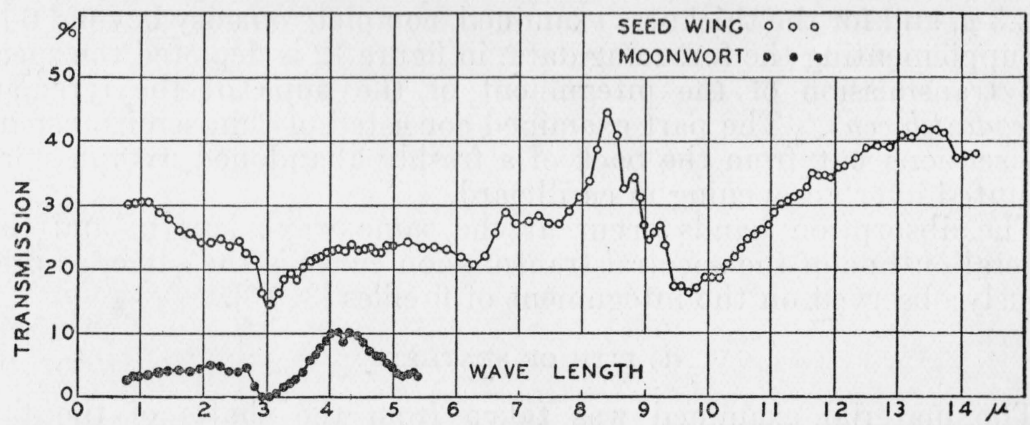

Figure 9.

It was difficult to obtain measurements on this (semitranslucent) material, because of scattering of radiation. The absorption spectrum is similar to that of the other cellulose materials examined.

\section{(e) SEED WING}

In figure 9 is depicted the spectral transmission curve of the delicate, silky, white, iridescent wing which is attached to the seed of the cotton tree (Pithecoctenium echinatum). The sample-which was collected by W. W. C. in Sumatra-was dry, and because of its large 
size (4 by $8 \mathrm{~cm}$ ) permitted an examination of a large area that was relatively homogeneous and transparent.

In this group of cellulose materials (one artificial, the others natural) the infrared absorption spectrum shows two strong bands, at 3 and $6.1 \mu$, respectively, which may be owing to the presence of moisture or perhaps OH-groups. Other bands (e. g., at 3.45 and $6.9 \mu$ ) are found in hydrocarbons.

Considered as a whole, the cellulose materials appear to have a characteristic absorption spectrum, as was previously found in other groups of chemical compounds, for example, alcohols, etc.

\section{PROTEINS}

The proteins are complex compounds of $\mathrm{C}, \mathrm{H}, \mathrm{N}, \mathrm{O}$, and $\mathrm{S}$. The material examined was the impure animal tissue. In a previous communication [15], data were given on the ultraviolet transmission of a sample of animal tissue.

\section{(a) CHITIN}

This is a complex nitrogenous substance, of unknown chemical structure, which forms the outer, horny, amorphous integument of insects. In a previous communication [3, 10] infrared absorption spectra were given of the dried covering of the luminous organs of several species of fireflies. For completeness of exposition of the absorption spectra of proteins, reference to this earlier work is made in the present paper.

Aside from the inhomogeneity, and the brown color of some samples, which reduced the transmission in the visible spectrum, a conspicuous feature of the absorption spectrum of chitin is a relatively high transparency in the region of 1 to $2.5 \mu$, and, to a less degree, at 4 to $5.5 \mu$, with a strong complex absorption band (opacity) at 2.9 to $3.3 \mu$, and for the thickness examined, complete opacity beyond $6 \mu$.

Supplementing the foregoing data, in figure 12 is depicted the spectral transmission of the integument of the pupa of the lyreman (Cicada tibicen). The part examined consisted of thin semitransparent sections cut from the back of a freshly abandoned nymph-skin, mounted over an opening in cardboard.

The absorption bands occur at the same wave length, and the general outline of the spectral transmission curve is the same, as previously observed on the integument of fireflies $[3,10]$.

\section{(b) PITH OF FEATHERS}

The material examined was taken from the shafts of the tail fe athers of a turkey buzzard, common about Washington. The individual sections of the pith, which are somewhat cylindrical in outline, and fairly translucent, were cut longitudinally and several such sections were spread out in a row over an opening (5 by $15 \mathrm{~mm}$ ) cut in cardboard.

Transmission data on 2 samples of pith of feathers are given in figure 10 . The transmission curves show two strong absorption bands, at 3 and at $6 \mu$, respectively. Beyond $6 \mu$ the absorption consists of numerous fine lines. The low transmission at $1 \mu$ is owing to scattering, for which no correction was made. 
(c) FISH BLADDER

The air bladder of a fish (a croaker, taken from Chesapeake Bay), was examined after mounting over a perforated cardboard support and drying for several days.

The transmission curve (fig. 10) shows strong absorption at 3 and at $6 \mu$, but the material was too inhomogeneous to permit an accurate determination of the maxima of the absorption bands.

\section{(d) DRAGON FLY WING}

The large membraneous wings of a dragon fly (Agrion) are relatively homogeneous (between the veins) and can be made into windows that permit viewing objects without distortion. Such a specimen was used to obtain the data shown in figure 11.

The transmission curve is interesting in showing an absorption band at about $1.3 \mu$, which is unusual for a thin layer of material. Other sharply defined absorption bands occur at 3.0, 3.5, 6.1, and

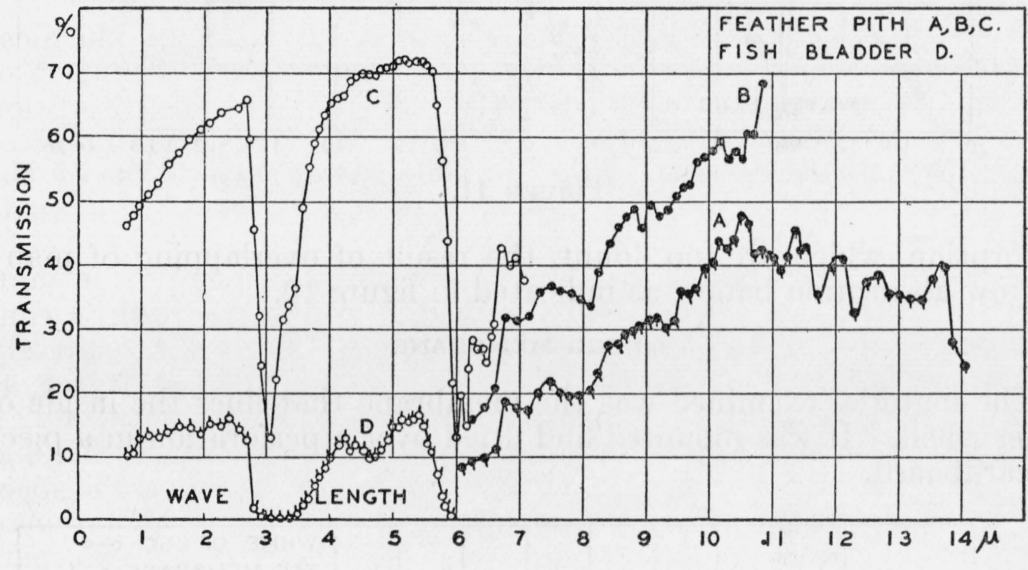

Figure 10.

$6.5 \mu$. The specimen was evidently too thin to permit observing the fine absorption bands, at wave lengths longer than $6.5 \mu$, that occur in the pith of feathers and in other proteins [20].

(e) BAT WING

Transmission data on a thinly stretched, dried wing of a bat are given in figure 11. The highly diffusing character of the sample is evident by the general upward trend of the transmission curve between 0.8 and $5.5 \mu$. Strong absorption bands occur at 3.0, 3.5, 6.0, $6.1,6.5$, and $6.9 \mu$, in common with the other protein material examined.

\section{(f) EGG ALBUMIN}

In figure 12 is depicted the spectral transmission of a film of white of egg. The specimen was prepared by allowing a film of the egg. albumin to dry upon a plate of quartz, from which it was peeled and mounted over a slit in a piece of cardboard.

The film was highly transparent in the visible and to $2.5 \mu$ in the infrared. 
There is a strong absorption band, with an unresolved maximum extending from 2.95 to $3.5 \mu$, and a similar band with maxima at 5.9, 6.0 , and $6.2 \mu$. Beyond $7 \mu$ the film shows wide bands of selective

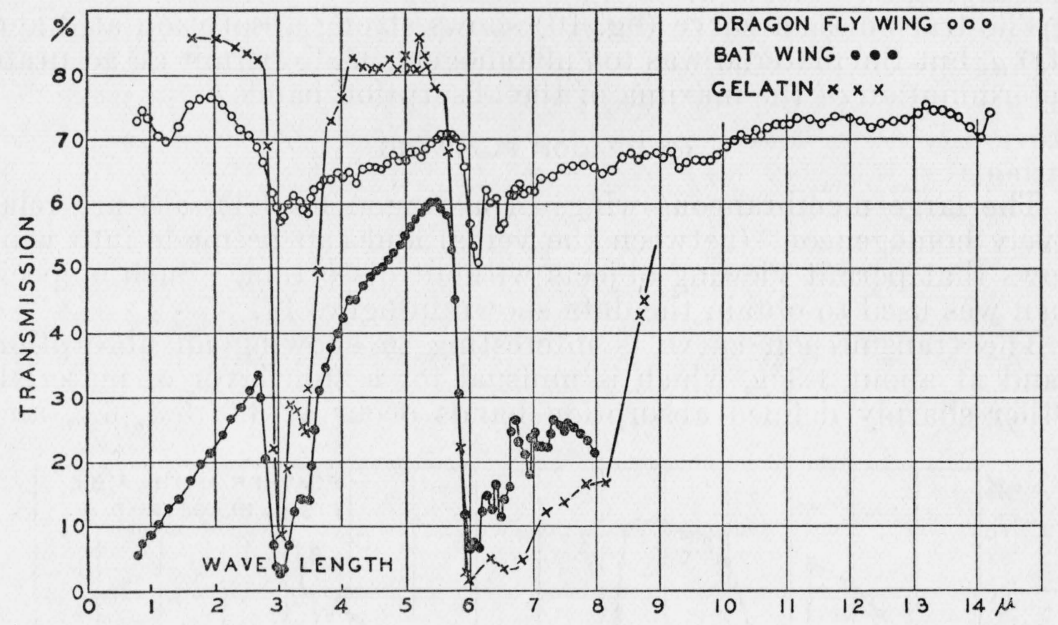

Figure 11.

absorption, which are, no doubt, the result of overlapping of many narrow absorption bands, as indicated in figure 10 .

\section{(g) EGG MEMBRANE}

The material examined was the membrane that lines the inside of an eggshell. It was mounted and dried over a perforation in a piece of cardboard.

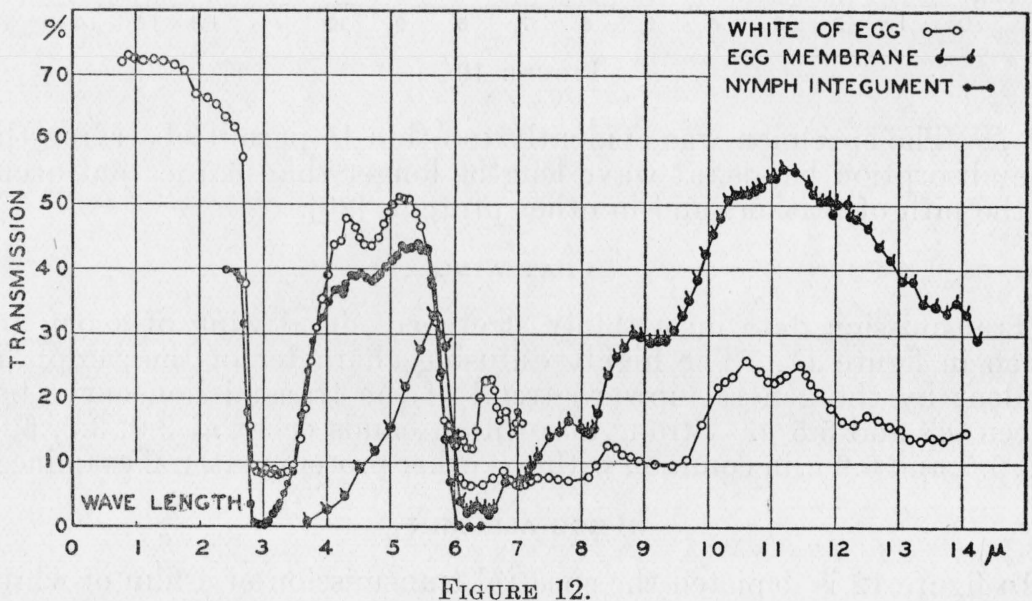

Owing to the highly diffusing character of the material, no absorption bands could be identified for wave lengths shorter than about 6 $\mu$ (fig. 12). For longer wave lengths the absorption bands are similar to those of egg albumin and other proteins examined, 
(h) GELATIN

This substance belongs to the albumins, the chemical composition of which is unknown. They contain $\mathrm{C}, \mathrm{H}, \mathrm{O}, \mathrm{N}$, and $\mathrm{S}$. The transmission curve of dehydrated commercial material previously examined [3] is given in figure 11 for completeness of exposition of the subject.

Considered as a whole, the proteins examined exhibit a characteristic absorption spectrum (with individual differences of course) as previously observed in groups of chemical compounds, such as the carbonates, alcohols, and fatty acids.

Characteristic absorption maxima occur at 3.0, 3.43, 4.2 4.6, 5.9, $6.3,6.8,7.3,8.1,9.2,11.0$, and $12.2 \mu$. Some of these maxima have

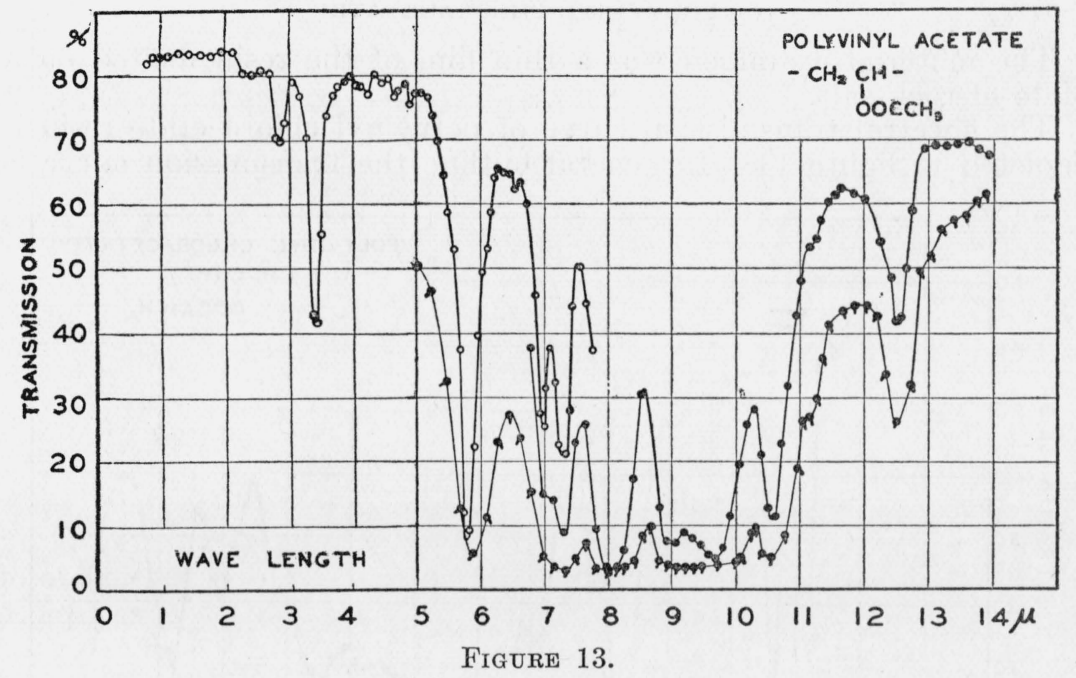

been identified with $\mathrm{CH}_{2}$ and $\mathrm{OH}$ groups. The strong absorption at 6 to $8 \mu$ is noted in hydrocarbons modified by $\mathrm{NO}_{2}$ groups.

\section{SPECTRAL-TRANSMISSION DATA ON MISCELLANEOUS SUBSTANCES}

Under this caption are gathered the infrared spectral absorption curves of a number of compounds and substances which are of interest for miscellaneous reasons.

Some of the substances were examined in connection with a study of Raman's [1] theory of scattered radiation. Others have an interest in connection with the data on the rubber and cellulose materials. The examination includes also several newly developed synthetic resins, which have interesting absorption spectra. In several instances the substances were examined to obtain data in the spectral region of 12 to $15 \mu$ not resolved in a previous examination [11].

\section{VINYL RESINS}

The basis of the vinyl $\left(\mathrm{CH}_{2}=\mathrm{CH}\right)$ resins is ethylene, $\mathrm{C}_{2} \mathrm{H}_{4}$. They are amorphous, polymeric bodies formed by the action of ultraviolet light [16]. 


\section{(a) POLYVINYL ACETATE}

In figure 13 data are given on several samples of polyvinyl acetate resin. The specimens were prepared by melting some of the resin on, or between, plates of rock salt. In this manner a thin homogeneous film (probably 0.01 to $0.02 \mathrm{~mm}$ in thickness) of high transparency in the visible spectrum was easily obtained. This material has a high absorption between 7 and about $11 \mu$, as previously observed in ethylene [11]. However, the details of the absorption spectra are considerably different. For example, the prominent absorption bands at $3.28,5.3$, and $6.98 \mu$, respectively, in ethylene are shifted to 3.45 , $5.8,6.98$, and $7.3 \mu$, respectively, in polyvinyl acetate.

\section{(b) POLYVINYL CHLORACETATE}

The material examined was a thin film of the resin melted on a plate of rock salt.

The spectral transmission curve of polyvinyl chloracetate resin is depicted in figure 14. In general outline the transmission curve is

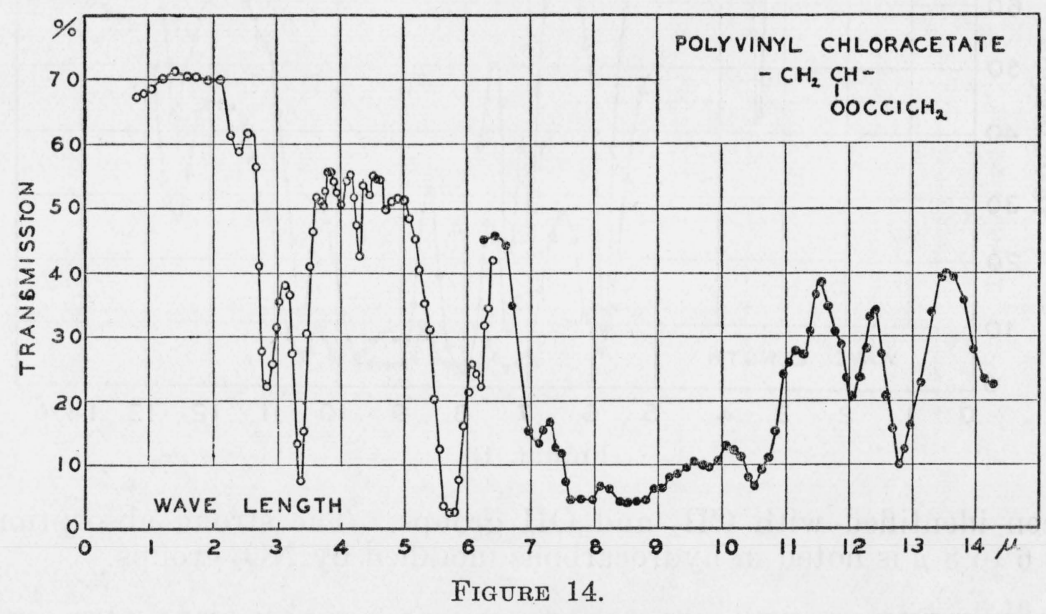

similar to that of polyvinyl acetate, but at wave lengths longer than $7 \mu$ the absorption maxima are different, particularly at $12 \mu$.

\section{GLYPTAL RESIN}

The name "Glyptal" is used [16] to designate resinous bodies that are produced from glycerol (a polyhydric alcohol) and organic acidstartaric acid, citric acid, phthalic acid.

The point of interest in studying this substance is the effect of resinous condensation upon the hydroxyl groups, which, as previously observed [11], have a characteristic absorption at 2.9 to $3 \mu$.

The glyptal resin examined was obtained commercially as a white powder of unknown purity. Upon heating some of the powder (between rock-salt plates) in a bunsen flame a transparent film, tinged slightly yellow, was obtained.

The absorption spectrum, shown in figure 15 , is quite different from that of the other two resins examined, as is to be expected. 
The sharp absorption band at $2.9 \mu$, conspicuous in substances containing OH-groups, is to be noted. The less conspicuous bands at 3.43 and $6.86 \mu$, respectively, observed in substances containing: $\mathrm{CH}_{2}$ and $\mathrm{CH}_{3}$ groups are also to be noted. The strong band at 5.8 $\mu$ has been found in numerous substances containing $\mathrm{C}=\mathrm{O}$ linkages.

\section{SHELLAC}

Two samples of shellac (fig. 16) were prepared by melting some of the dry flakes of the commercial material on a plate of rock salt. The resulting film was very thin, showing only a trace of color. The spectral transmission of this material is of interest in connection with a study of the artificial resins and with the other plant materials examined.

Conspicuous among the absorption bands is the maximum at 2.9 $\mu$ observed in substances containing OH-groups; also the maximum

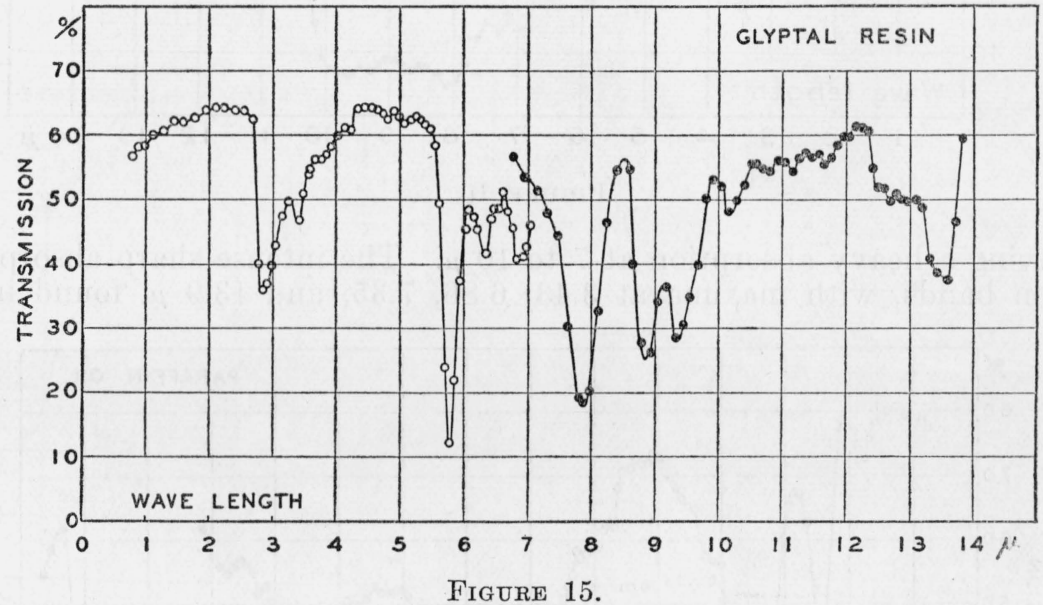

at $5.85 \mu$ in substances having $\mathrm{C}=\mathrm{O}$ linkages; and the ever-recurring, approximately harmonic bands at $3.43,6.86,(7.3)$ and at $13.9 \mu$ observed in hydrocarbons containing $\mathrm{CH}_{2}$ and $\mathrm{CH}_{3}$ groups.

\section{PARAFFIN OIL}

The spectral transmission of a thick colorless paraffin oil (trade name Nujol) is given in figure 17 .

The infrared transmission curve, with maxima of absorption at $1.8,2.4,3.43,4.2,5.8$ to $6.2,6.86,7.3,7.8,8.7,10.4,11.2,11.8,12.4$, 13.0 , and $13.9 \mu$, is practically identical with that of the petroleum, distillates previously examined [11]. The spectral transmission, extending from 0.6 to $2.5 \mu$ of a 1-cm layer of this oil is given in an earlier paper [17].

\section{SPERM OIL}

The sample of sperm oil (thickness $0.25 \mathrm{~mm}$ ) was practically colorless. An examination of this substance was of interest in connection with earlier studies [3,17] of other animal and of vegetable oils.

$6669-35-8$ 
The infrared spectral transmission (fig. 18) differs mainly from that of the paraffin oils, and is similar to that of the fatty acids, in

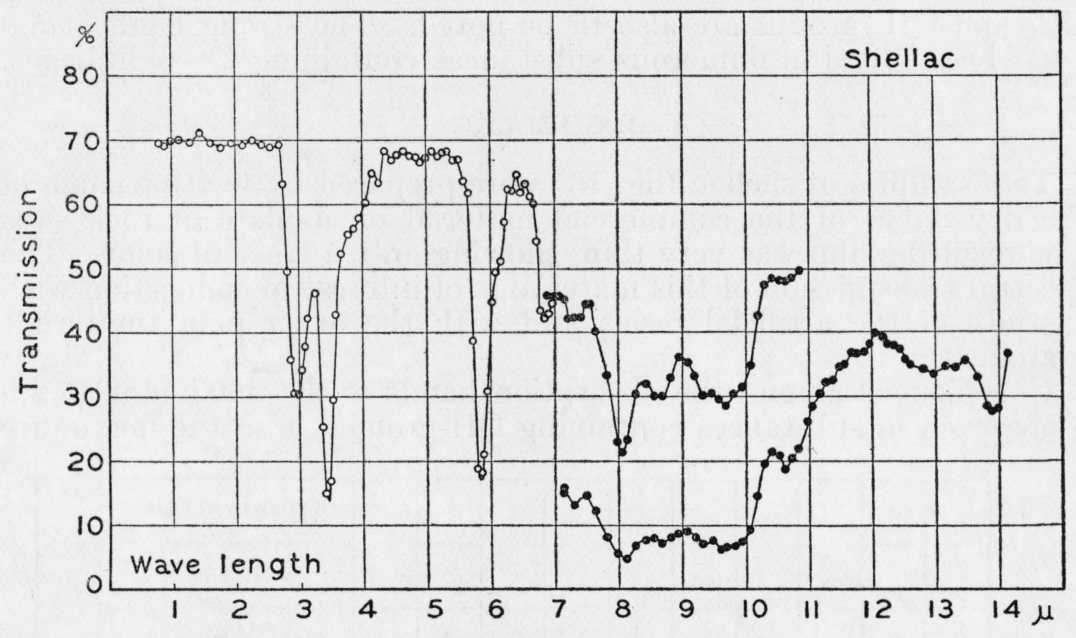

Figure 16.

having a heavy absorption at 7 to $10 \mu$. The intense sharp absorption bands, with maxima at $3.43,6.86,7.35$, and $13.9 \mu$, found in

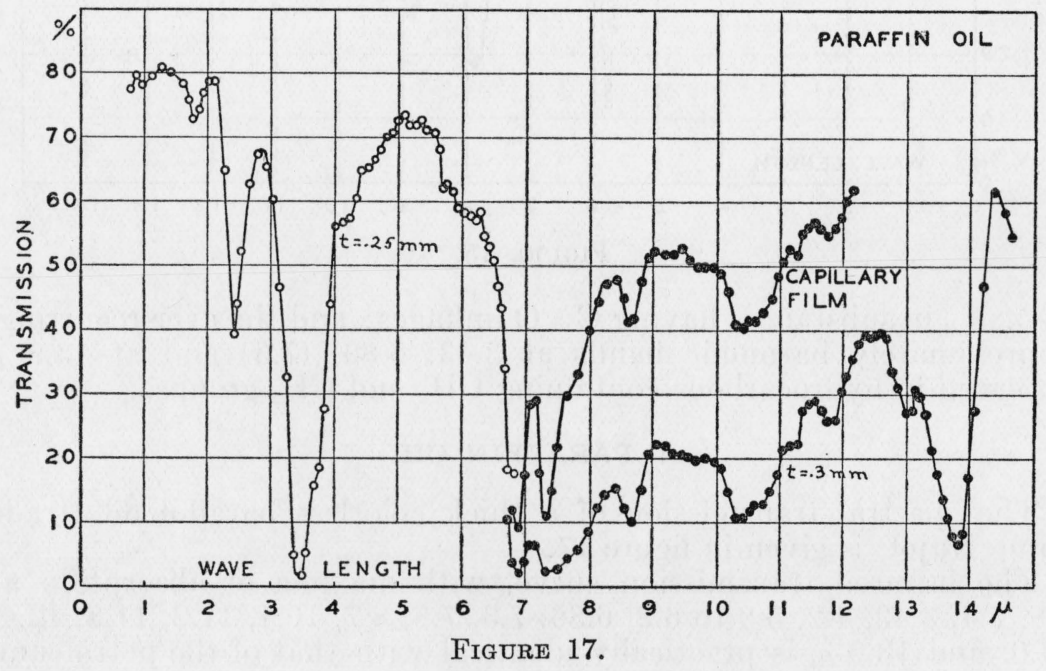

hydrocarbons rich in $\mathrm{CH}_{2}$ and $\mathrm{CH}_{3}$ groups, and the band at $5.8 \mu$ found in substances containing the $\mathrm{C}=\mathrm{O}$ bond [3], are to be noted.

\section{LINSEED OIL}

This material was examined (fig. 19) to obtain a check on the spectrometer calibration and to extend the spectral range of earlier measurements [3] which stopped at $9 \mu$. The sharp maximum at 5.8 
$\mu$ and the harmonic bands at $3.43,6.86$, and $13.9 \mu$ were discussed in the earlier paper.

\section{CARBON TETRACHLORIDE}

Carbon tetrachloride was examined [19] in the spectral region between 7 and $14 \mu$ (fig. 19) in connection with the study of Raman's

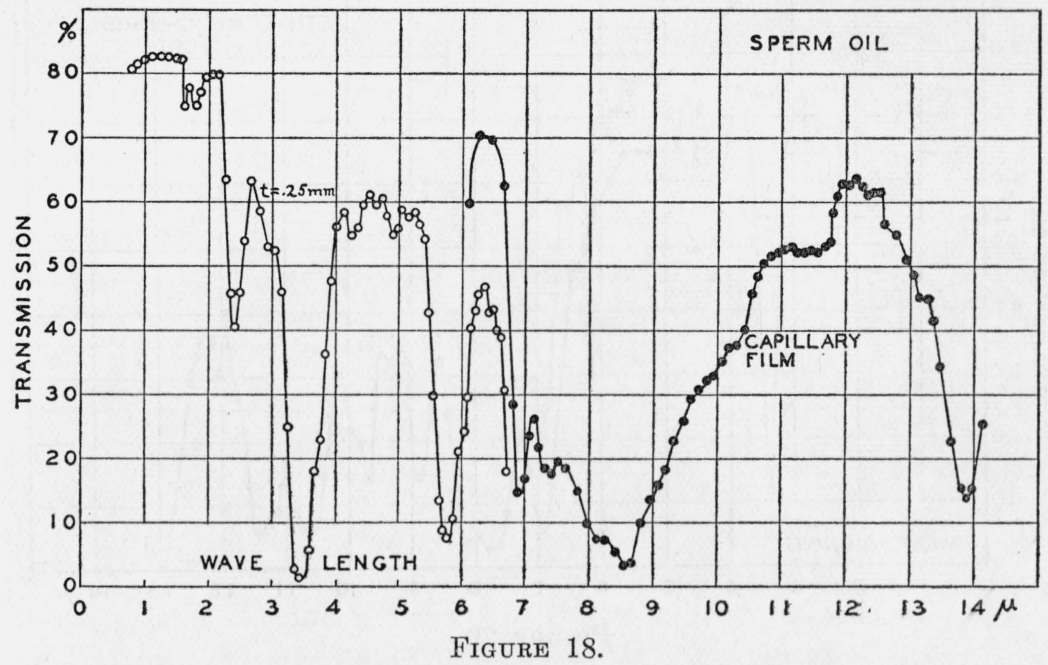

theory [18]. While the bands near 8 and $10 \mu$ had been previously mapped, the heavy absorption at $13 \mu$ was published [11] as a wide unresolved band extending from 12.4 to $13.6 \mu$.

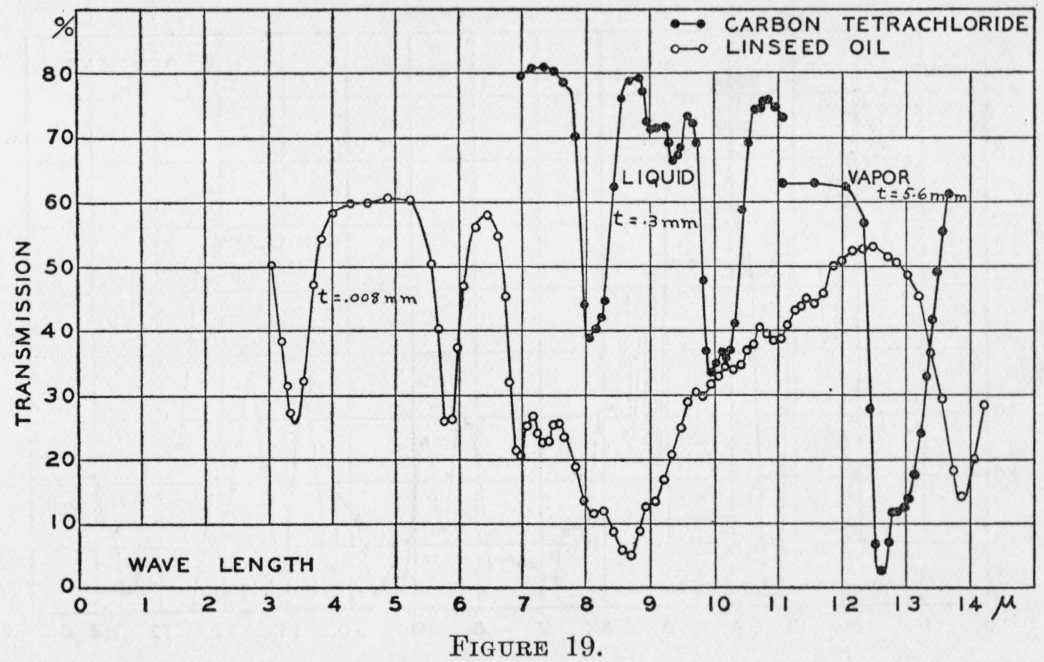

In the region of $13 \mu$ the absorption is so great that a conveniently produced thin, liquid film is completely opaque. An examination was, therefore, made of a column of the vapor (thickness $5.6 \mathrm{~mm}$ ) which shows two absorption maxima in this region, at about 12.6 and $12.8 \mu$, respectively. 
In this test the vapor was obtained by sealing a small amount of the liquid in a rock-salt cell, at room temperature and at atmospheric pressure.

The maxima of the strong absorption bands of carbon tetrachloride observed by Coblentz [11] and subsequently by Coblentz and Stair

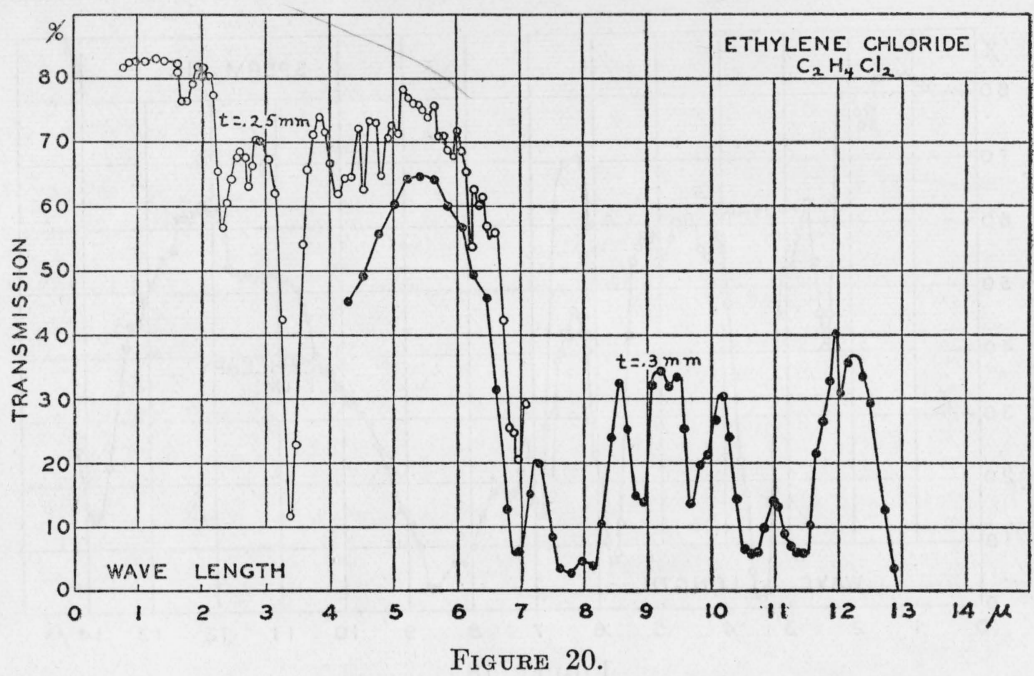

[19] and the values calculated by Langer and Meggers [18] from their observations of the Raman scattering are given in table 1 . The differences between the observed and the calculated values are entirely within the limits of accuracy of the observed data, which in some cases

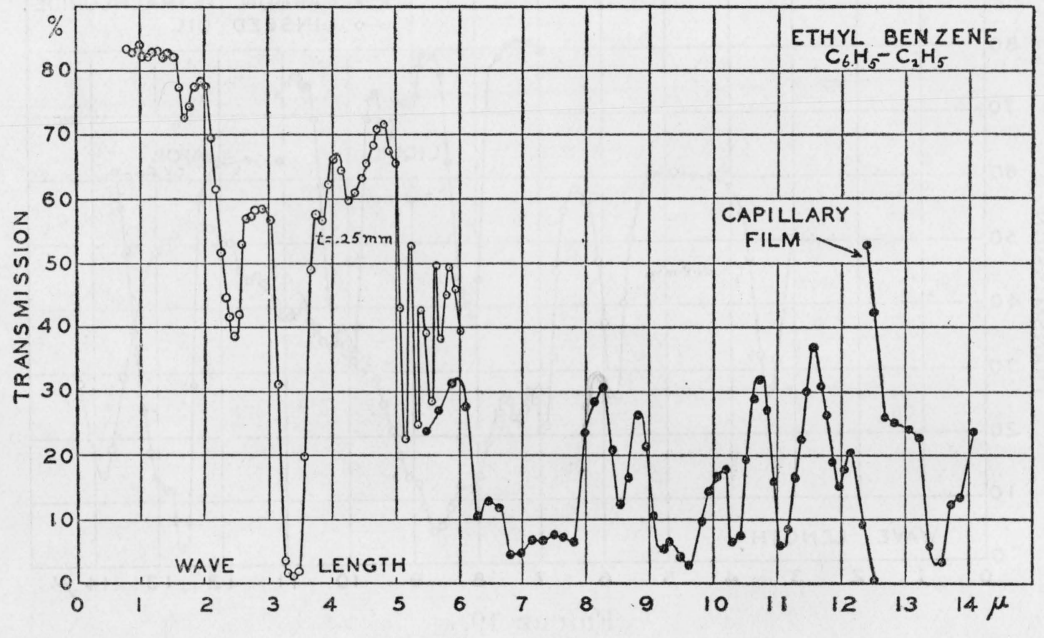

Figure 21.

suffer from lack of resolution of complex absorption bands. For example, if the band were completely resolved, the maximum absorption which appears to be at about $13.1 \mu$ would, no doubt, be found at longer wave lengths. Again, the selective absorption at 9.0 to 
$9.5 \mu$ may be a complex of three absorption bands, instead of two bands, as it appears from the transmission curve.

TABLE 1.-Calculated and observed maxima of selective absorption of carbon tetrachloride

\begin{tabular}{|c|c|}
\hline $\begin{array}{c}\text { Calculated } \\
\text { (Langer and } \\
\text { Meggers) }\end{array}$ & $\begin{array}{c}\text { Observed } \\
\text { (Coblentz } \\
\text { and Stair) }\end{array}$ \\
\cline { 2 - 2 }$\mu$ & $\mu$ \\
\hline$\mu$ & 13.10 \\
13.18 & 12.67 \\
12.66 & 10.22 \\
10.23 & 9.95 \\
9.92 & 9.32 \\
9.20 & 9.08 \\
9.06 & 8.20 \\
8.21 & 8.02 \\
8.01 & 6.57 \\
6.59 & 6.45 \\
6.50 & \\
6.46 & \} \\
\hline
\end{tabular}

\section{ETHYLENE CHLORIDE}

The infrared spectral transmission curve of ethylene chloride, is depicted in figure 20. It was examined for comparison with ethylene bromide previously studied [11].

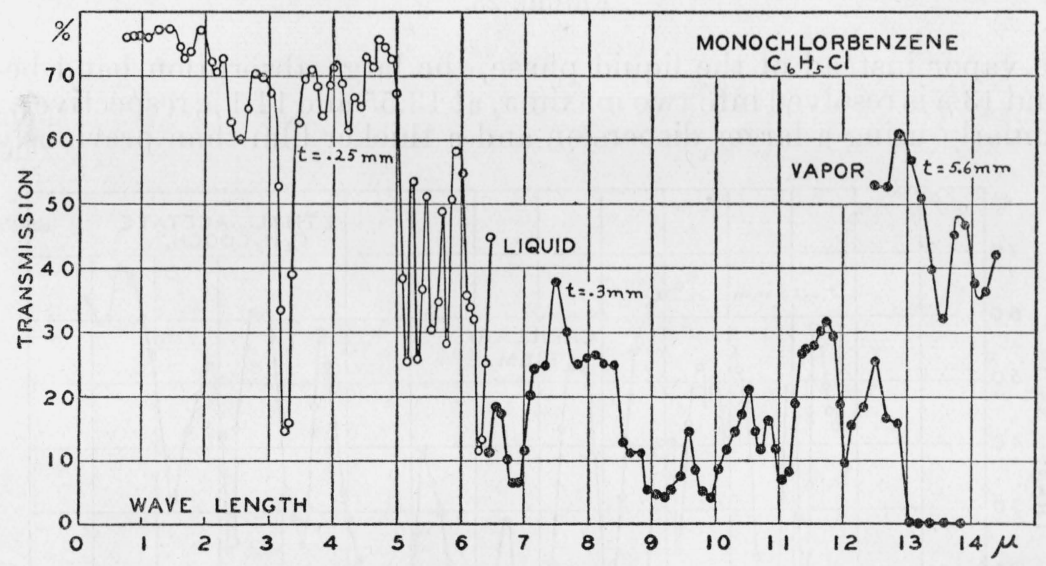

Figure 22.

In addition to the intense absorption bands in the region of 3.4 and $6.9 \mu$, observed in ethylene and its derivatives, there are new absorption bands at wave lengths longer than $8 \mu$.

\section{ETHYLBENZENE}

The spectral transmission of ethylbenzene is shown in figure 21 . This supplements the data previously published, particularly in the region of 5 to $6 \mu$, where the use of a fluorite prism made it possible to resolve the selective absorption into a group of sharp bands not shown in the earlier work. 


\section{MONOCHLORBENZENE}

The infrared transmission of monochlorbenzene depicted in figure 22, supplements the measurements previously published [11]. Using

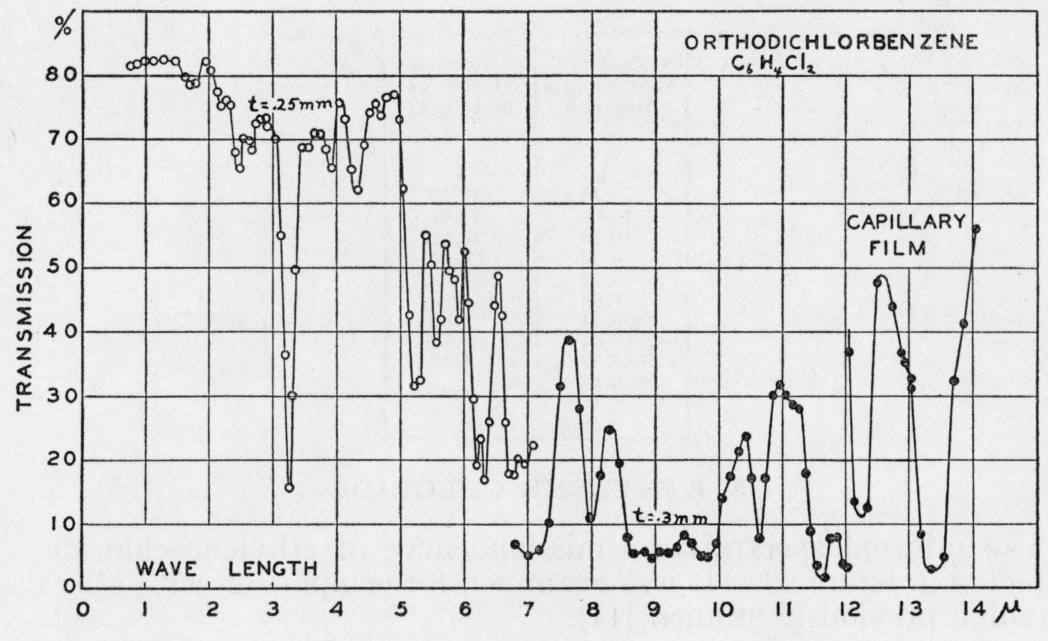

Figure 23.

the vapor instead of the liquid phase, the large absorption band beyond $13 \mu$ is resolved into two maxima, at 13.55 and $14.1 \mu$, respectively. Similarly using a larger dispersion and a thicker film than previously

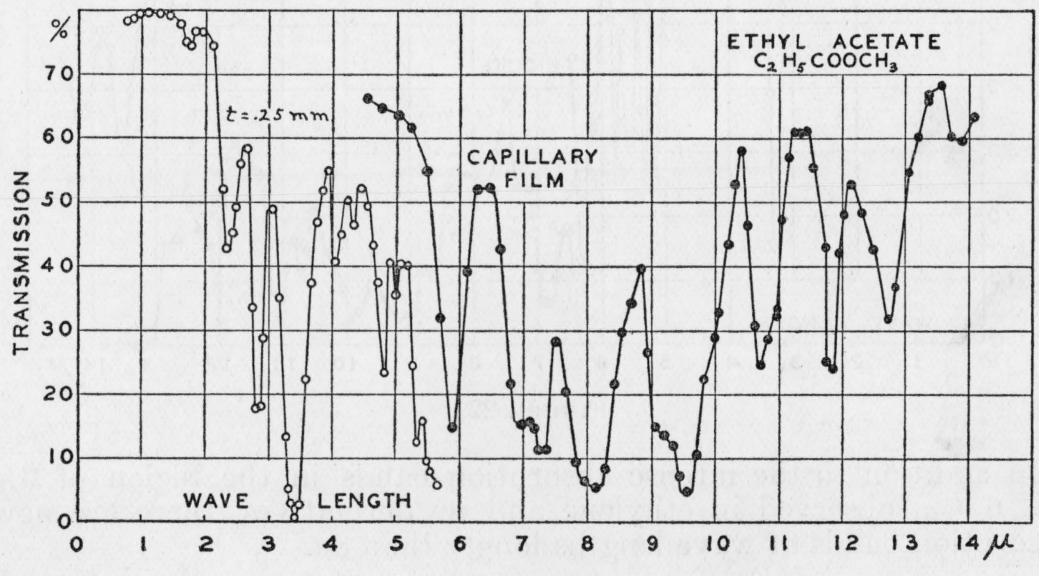

Figure 24.

employed, the selective absorption at 2 to $6 \mu$ is resolved into numerous fine lines.

11. ORTHODICHLORBENZENE

In figure 23 is depicted the infrared spectral transmission of orthodichlorbenzene. The spectrum consists of numerous narrow bands of selective absorption, as in the preceding compound. 

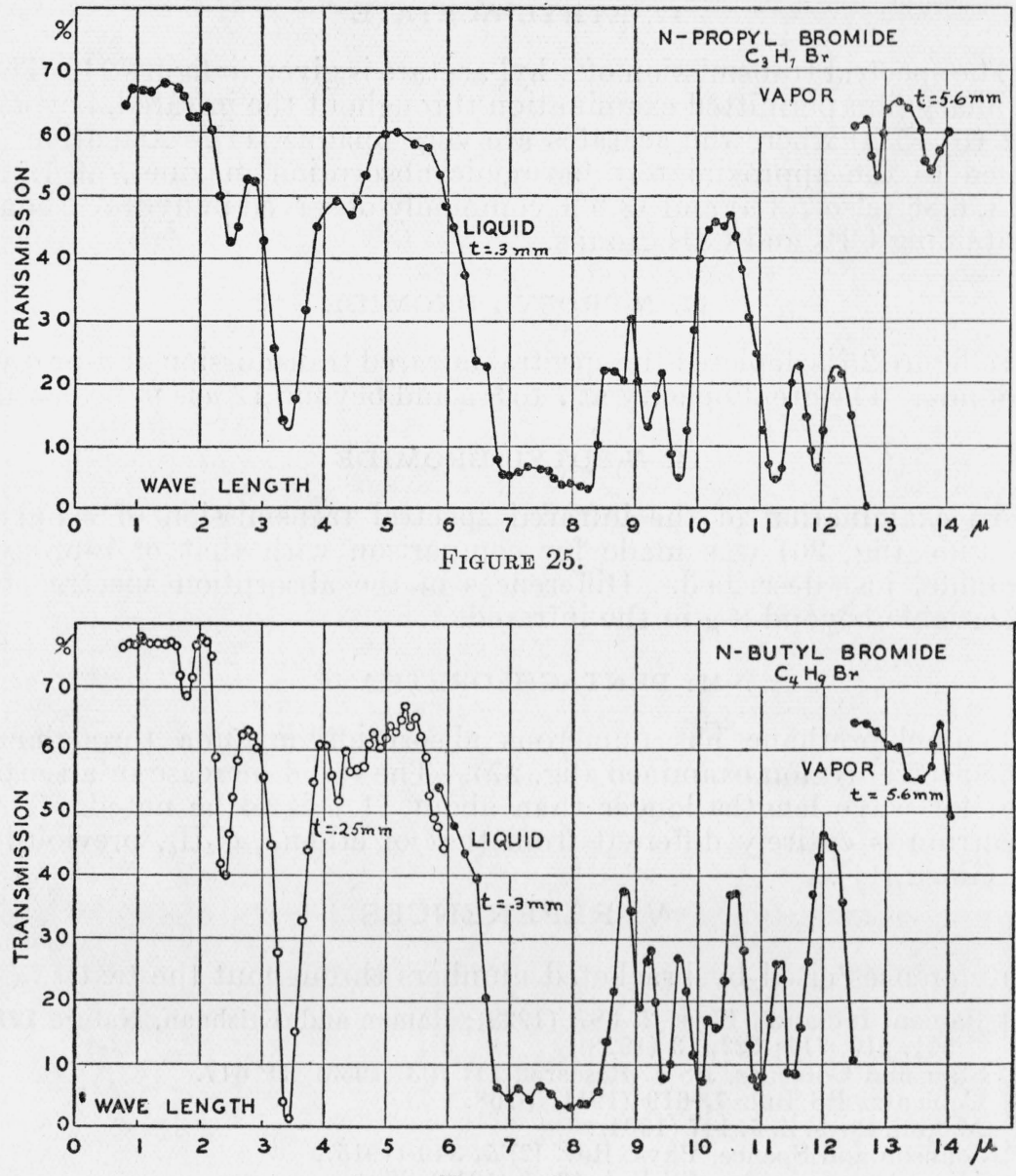

Figure 26.

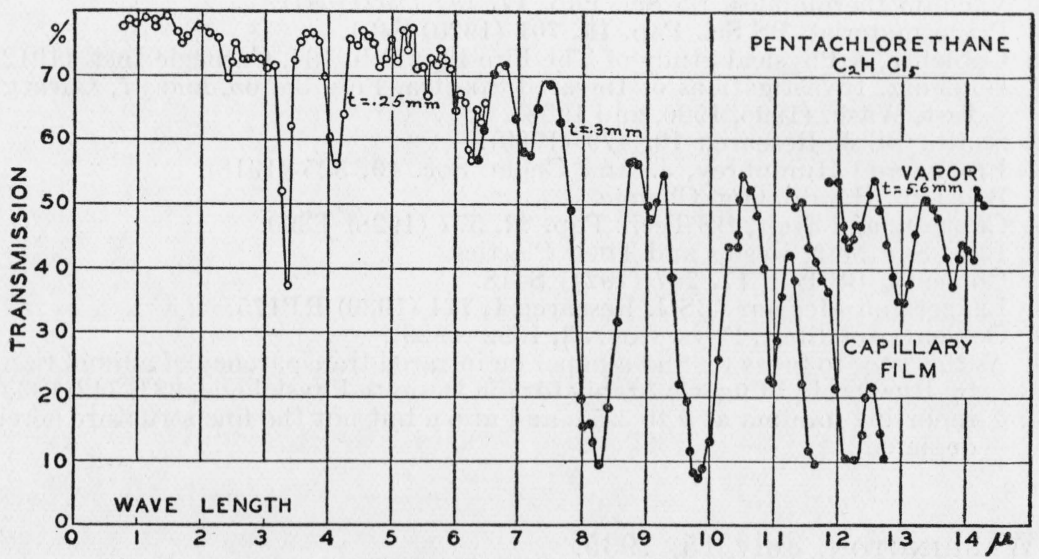

FigURe 27. 


\section{ETHYL ACETATE}

The spectral transmission of ethyl acetate is given in figure 24. The capillary film permitted examination throughout the infrared, beyond $5 \mu$ (to $15 \mu$ ) where the acetates are very opaque [11]. Attention is called to the approximately harmonic absorption maxima, at 1.71, $3.43,6.86$ (also $7.3 \mu$ ) and $13.9 \mu$, commonly observed in hydrocarbons containing $\mathrm{CH}_{2}$ and $\mathrm{CH}_{3}$ groups.

\section{N-PROPYL BROMIDE}

In figure 25 is depicted the spectral infrared transmission of $n$-propyl bromide. The great opacity at 7 to $8 \mu$ and beyond $12 \mu$ is to be noted.

\section{N-BUTYL BROMIDE}

An examination of the infrared spectral transmission of $n$-butyl bromide (fig. 26) was made for comparison with that of $n$-propyl bromide, just described. Differences in the absorption spectra are observable beyond $8 \mu$ in the infrared.

\section{PENTACHLORETHANE}

Pentachlorethane has numerous absorption maxima throughout the spectral region examined (fig. 27). The rapid increase in absorption for wave lengths longer than about $11 \mu$ is to be noted. The spectrum is entirely different from that of ethane, $\mathrm{C}_{2} \mathrm{H}_{6}$, previously examined [11].

\section{REFERENCES}

References cited by bracketed numbers throughout the text:

[1] Raman, Indian J. Phys. 2, 387 (1928); Raman and Krishnan, Nature 121, 501, 619, 711; 122, 13 (1928).

[2] Stair and Coblentz, BS J. Research 11, 703 (1933) RP 617.

[3] Coblentz, BS Bul. $\boldsymbol{\gamma}, 619$ (1911) S168.

[4] Magini, Phys. Z. 5, 147 (1904).

[5] Johnson and Spence, Phys. Rev. [2] 5, 349 (1915).

[6] Mirror spectrometer, BS Bul. 10, 1 (1913) S204.

[7] Ironclad galvanometers, BS Bul. 13, 423 (1916) S282.

[8] Vacuum thermopiles, BS Sci. Pap. 1\%, 187 (1921) S413.

[9] Prism material, BS Sci. Pap. 16, 701 (1920) S401.

[10] Coblentz, A Physical Study of The Fire Fly, Pub. 164, Carnegie Inst. (1912).

[11] Coblentz, Investigations of Infrared Spectra, Pub. 35, 65, and 97, Carnegie Inst. Wash. (1905, 1906, and 1908).

[12] Smith, BS J. Research 10, 479 (1933).

[13] Brooks and Humphrey, J. Am. Chem. Soc. 40, 825 (1918).

[14] Beilstein, Handb. Org. Chemie.

[15] Coblentz and Stair, BS Tech. Pap. 22, 577 (1928) T369.

[16] Ellis, Synthetic Resins and Their Plastics.

[17] Coblentz, BS Bul. 1\%, 267 (1921) S418.

[18] Langer and Meggers, BS J. Research 4, 711 (1930) RP175.

[19] Coblentz and Stair, Phys. Rev. 33, 1092 (1929).

[20] As this goes to press we find a paper on infrared transparency of animal tissue by Rucker, in Pflüger's Archiv für die Desante Physiologie, 281, 742(1933), reporting minima at 3 to $3.5 \mu$ and at $6 \mu$ but not the fine structure herein depicted.

WAShington, July 15, 1935. 